\title{
CORRIGENDUM \\ Beyond planning and architecture: the urban project in Sydney
}

\section{Peter John Cantrill and Philip Thalis}

URBAN DESIGN International (2006) 11, 67. doi:10.1057/palgrave.udi.9000165

URBAN DESIGN International, 2005, 10(3-4): 147-163.

The above paper was published with an incorrect affiliation for the authors. The correct affiliation is as follows:
Faculty of Design, Architecture and Building, School of Architecture, University of Technology, Sydney, PO Box 123, Broadway NSW 2007, Australia.

E-mail: philip.thalis@uts.edu.au; peter.john.cantrill@ uts.edu.au 